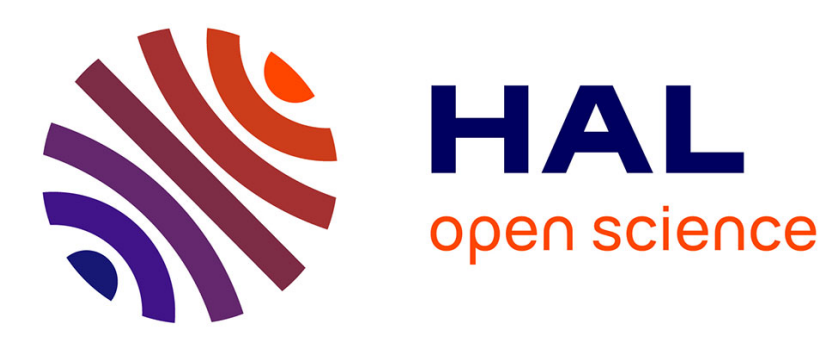

\title{
Fracture Surface Energy Measurement at High Crack Speed Using a Strip Specimen: Application to Rubber Toughened PMMA
}

\author{
C. Fond, R. Schirrer
}

\section{- To cite this version:}

C. Fond, R. Schirrer. Fracture Surface Energy Measurement at High Crack Speed Using a Strip Specimen: Application to Rubber Toughened PMMA. Journal de Physique IV Proceedings, 1997, 07 (C3), pp.C3-969-C3-974. 10.1051/jp4:19973163 . jpa-00255453

HAL Id: jpa-00255453

https://hal.science/jpa-00255453

Submitted on 1 Jan 1997

HAL is a multi-disciplinary open access archive for the deposit and dissemination of scientific research documents, whether they are published or not. The documents may come from teaching and research institutions in France or abroad, or from public or private research centers.
L'archive ouverte pluridisciplinaire HAL, est destinée au dépôt et à la diffusion de documents scientifiques de niveau recherche, publiés ou non, émanant des établissements d'enseignement et de recherche français ou étrangers, des laboratoires publics ou privés. 


\title{
Fracture Surface.Energy Measurement at High Crack Speed Using a Strip Specimen: Application to Rubber Toughened PMMA
}

\author{
C. Fond and R. Schirrer \\ Institut Charles Sardon, 6 rue Boussingault, 67083 Strasbourg, France
}

\begin{abstract}
An experimental procedure is proposed to measure the lowest elastic stored energy density leading to a rapid crack propagation (RCP) in polymeric materials. A strip specimen with a blunt saw cut is uniformly loaded and a razor is pushed into the saw cut to initiate the crack. The very high crack velocity which is reached is measured with a resistive coating on the sample surface. Results obtained for a rubber toughened PMMA show that fracture energy for RCP at approximately $500 \mathrm{~m} / \mathrm{s}$ is much smaller than that in a quasi static tests. The material exhibits a ductile-brittle transition under particular loading conditions.
\end{abstract}

Résumé. Une essai est proposé pour mesurer les densité minimales d'énergie élastique de déformation conduisant à des propagations rapides de fissures dans des matériaux polymères. La géométrie de l'éprouvette est une bande ayant un trait de scie arondi chargée uniformément sur sa longueur. La fissure est amorcée par la percussion d'une lame de rasoir au fond du trait de scie. La vitesse de propagation de la fissure est mesurée par une jauge résisistive. Des résultats sont obtenus pour un PMMA "choc". Les énergies de rupture obtenues pour des vitesses de fissuration d'environ $500 \mathrm{~m} / \mathrm{s}$ sont bien inférieures à celles obtenues lors d'essais quasi statiques et montrent ur comportement fragile de ces matériaux sous certaines sollicitations.

\section{INTRODUCTION}

Tough materials are usually tailored to dissipate as much energy as possible in a damaged region which in turn must be as large as possible at an initial crack tip dynamically loaded [1]. In the ideal case, the consumed energy remains high after the propagation has started, leading to stable crack growth. Unfortunately, at very high loading rates or after the crack propagation has started, the energy consumed may be much lower than in the static case: the energy loss due to internal friction decreases and the yield stress increases, and the plastic zone at the crack tip may become very small. This is the well known ductile-brittle transition depending on the strain rate at the crack tip. The life time of the sample (or the real structure) is then related to the material characteristics at crack initiation and to those during a rapid crack propagation (RCP). A practical situation in which RCP has important consequences is the case of creep crack growth in pressured polymer pipes followed by unstable crack propagation [2, $3,4]$. The choice of an adequate tough polymer is then a compromise between these two fracture energies (initiation and propagation) and other usual properties like Young's modulus, glass transition temperature, etc. A precise measurement of the minimum strain energy density leading to a RCP is of great importance to design reliable real components.

The RCP fracture properties should be measured in a steady state propagation situation $[5,6,7]$. The control of the crack velocity is difficult as the crack can undergo successive starts and arrests (slipstick behaviour) due to the stable-unstable transition during propagation. Nevertheless, some particular sample geometry with less simple crack front analysis allow the control of the crack speed $[8,9]$. However, the most interesting material characteristics is the lowest strain energy density, the crack velocity and energy release rate at which $\mathrm{RCP}$ may take place. 


\section{STRIP SPECIMEN}

\subsection{Energy density}

Steady state crack propagation takes place in a strip band specimen when the stored energy density is uniform over the whole sample. Therefore the strip has a high length / height ratio. The static energy balance for an infinite long strip specimen is straightforward: an increment $\Delta \mathrm{a}$ of crack length unloads a part of the plane stressed specimen of width $\Delta \mathrm{a}$, whose strain energy density is $\mathrm{U}=\mathrm{B} \Delta \mathrm{a} h \sigma^{2}\left(1-v^{2}\right) / \mathrm{E}$ where B is the thickness of the plate, $\sigma=(\mathrm{u} / \mathrm{h}) \mathrm{E} /\left(1-v^{2}\right)$ is the load (Fig. $1), h$ the half height of the specimen, $v$ is the Poisson's ratio and $E$ the Young's modulus of the material at the strain rate $\partial \mathrm{u} /(\mathrm{h} \partial \mathrm{t})$. The quasi static energy release rate is then $\mathrm{G}_{0}=\mathrm{U} /(\mathrm{B} \Delta \mathrm{a})=\mathrm{h} \sigma^{2}\left(1-v^{2}\right) / \mathrm{E}$. The dynamic fracture energy $\mathrm{G}_{\mathrm{D}}$ is in most cases successfully analysed via linear elastic fracture mechanics (LEFM). Indeed, the yield stress increases with strain rate and therefore the size of the "plastic" zone at the crack tip decreases down to the level at which LEFM is valid. The initial crack length $\mathrm{a}_{0}$ must be greater than 2.5 times the strip height to avoid any boundary effect (Fig. 2). Indeed, if $a_{0}$ is smaller than that, then the driving force of the crack increases during the propagation. Our experiments have shown that the crack rapidly branches after initiation if the border effects are significant.

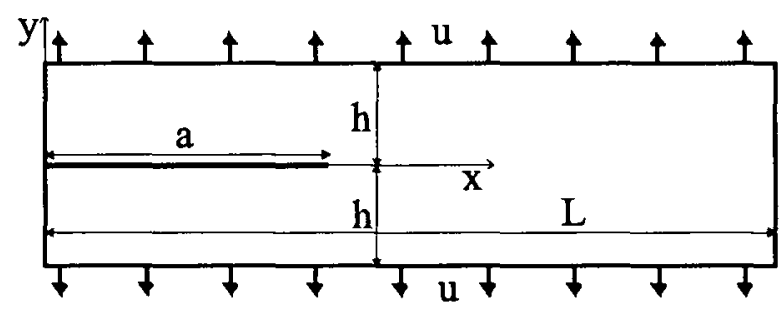

Figure 1: Strip specimen of length $L$ and height $h$ loaded in a plane stress state.

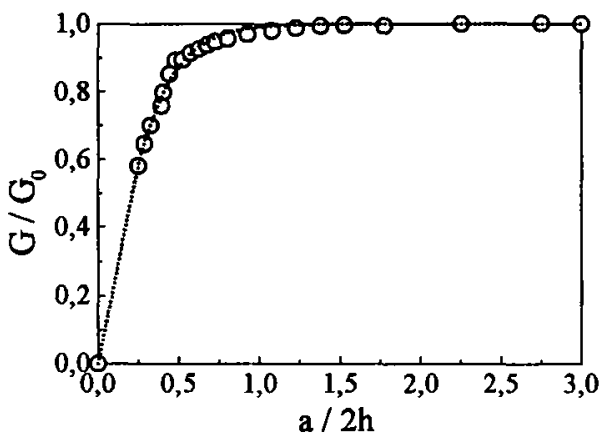

Figure 2: Normalised energy release rate vs. initial crack Figure 3: loading history of the material. The dark zone is length (static finite element analysis).

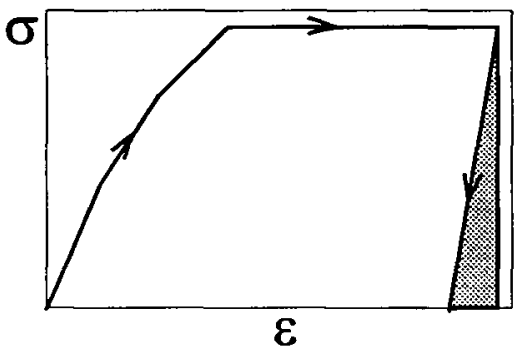

the dynamic elastic energy release

The level of the released energy depends on the dynamic moduli of elasticity (Fig. 3). For crack velocities close to the Rayleigh wave speed, the unloading of the band of width $\Delta \mathrm{a}$ does not concern the whole height as the elastic waves do not have enough time to reach the boundaries $[10,11,12]$. A dynamic correction $q$ to $G_{0}$ is then necessary to obtain the fracture energy. This correction depends on the crack velocity $\dot{a}=\partial \mathrm{a} / \partial \mathrm{t}$. The dynamic fracture energy during propagation is then $\mathrm{G}_{\mathrm{D}}=\mathscr{G}\left(\mathrm{a} / \mathrm{c}_{\mathrm{r}}\right) \mathrm{h} \sigma^{2}\left(1-v_{d y n}{ }^{2}\right) / \mathrm{E}_{\mathrm{dyn}}$ where $\left.\mathscr{q}_{(\mathrm{a}} / \mathrm{c}_{\mathrm{r}}\right)$ is the dynamic correction factor and 
$c_{\mathrm{T}} \approx(0.862+1.14 v)(\mu / \rho)^{1 / 2} /(1+v)$ is the Rayleigh wave speed. At first glance, the dynamic correction valid for a crack propagating at constant speed in an infinite body [13] can be used, and hence $c_{\mathrm{C}}\left(\mathrm{a} / \mathrm{c}_{\mathrm{r}}\right) \approx 1-\left(\mathrm{a} / \mathrm{c}_{\mathrm{r}}\right)$.

The tensile machine controls the load on the specimen. As relaxation times are short in most polymeric material, the load is maintained constant until the variation of strain becomes negligible within the duration of the experiment which is performed under constant tensile strain. The stresses inside the specimen are assumed to be constant, proportional to the load. The specimen length $\mathrm{L}$ is $200 \mathrm{~mm}$, the thickness is $2 \mathrm{~mm}$. The minimum half height $\mathrm{h}$ is $20 \mathrm{~mm}$.

\subsection{Experimental device}

The strip must be strained with a uniform displacement. This condition may be met by using a symmetrical geometry with 2 saw cuts. Unfortunately, the zone of steady state RCP is reduced because the crack rapidly enters into the far field region of the other crack tip. By twining two specimens in parallel ( Fig. 4) the length of steady state RCP is increased, the border effect being reduced to the free boundary (Fig. 5). The crack growth breaks the symmetry and the boundary conditions must be maintained during RCP. Therefore the position of the grips is firmly maintained by four screws and the tensile machine is unloaded, the load being transmitted to the screws. The elastic deformation of the screws decreases the initial load of nearly $20 \%$. The real value of the strain is measured by a strain gauge on each specimen, and the screws are tightened to obtain equals strains

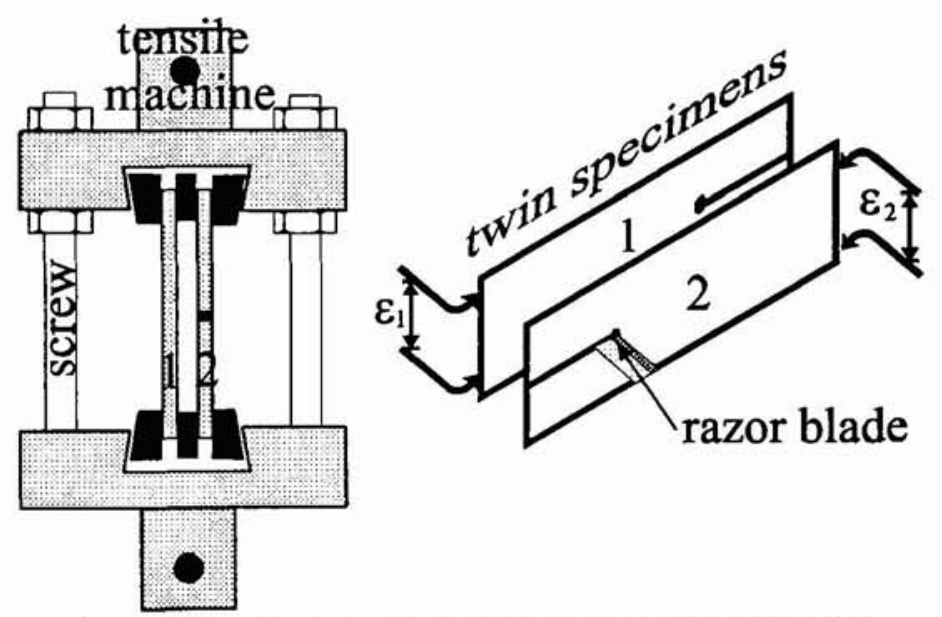

Figure 4: Experimental device with twin specimens loaded in parallel.

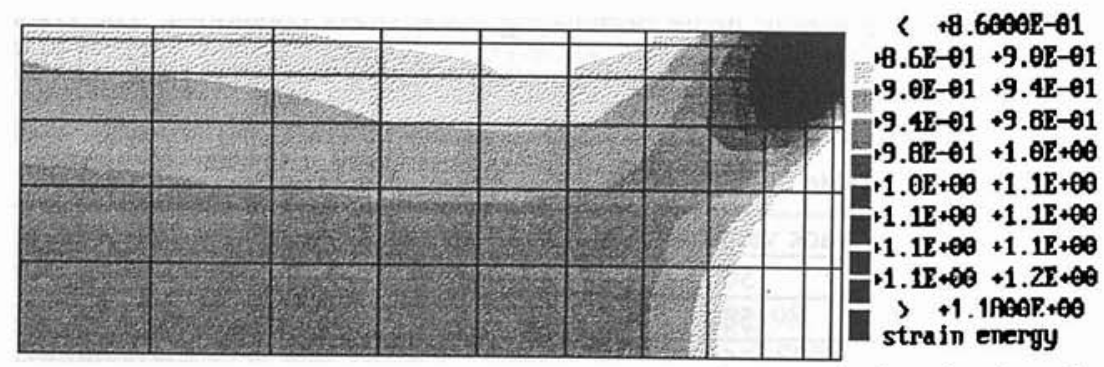

Figure 5: Isovalues of energy density obtained by finite element computation near a free boundary in a plate under plane stress tension (quarter mesh). 


\subsection{Initiation of $\mathrm{RCP}$}

A hole of $1 \mathrm{~mm}$ diameter is bored at the initial crack tip to have a blunt notch with a low level of plasticity and damage during the loading. The crack propagation is triggered by a razor blade which is pushed once the specimen is loaded and the screws tightened. Above a critical high level of energy density, the crack branches at a short distance (typically $1 \mathrm{~cm}$ ) from the initial crack tip. If the energy density is below a critical low level, the crack does not start to propagate. There is a short range $U_{\text {crit }}$ of energy density within which a single crack propagates in the symmetry axis of the specimen. The additional initial crack length made by the razor blade is at least $1 \mathrm{~mm}$ long, which corresponds to the size of the small damaged zone at the initial blunt crack tip. The impact energy and the strike speed of the razor blade are controlled by a falling weight system.

\subsection{Measurement of the crack velocity}

The crack velocity is measured during the test by means of a metallic layer coated on the specimen, whose resistance is measured (Fig. 6). As it is difficult to obtain a uniform metallic layer along the crack path, it is composed of controlled conducting and non conducting zones. The electric resistance is sampled at $150 \mathrm{kHz}$. This leads to approximately thirty measurements during a RCP. The sampling starts when the falling weight passes in front of a magnetic trigger.

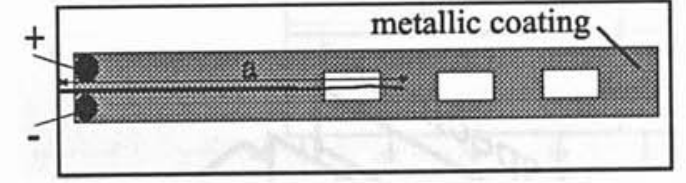

Figure 6: Resistive gage used to measure the crack length

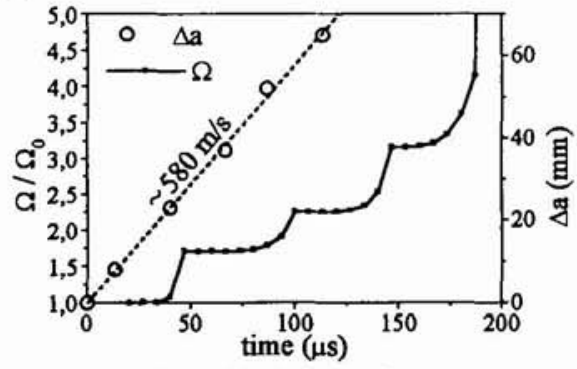

Figure 7: Typical resistance measurement and crack growth vs. time.

\section{EXPERIMENTAL RESULTS FOR A RUBBER TOUGHENED- POLYMETHYLMETHACRYLATE}

\subsection{Fracture energy during a RCP}

The size of the specimen was $\mathrm{L}=200 \mathrm{~mm}, \mathrm{~B}=2 \mathrm{~mm}$ and $\mathrm{h}=24 \mathrm{~mm}$. The material characteristics were $E_{\text {dyn }}=3.2 \mathrm{Gpa}, v=0.4, \rho=1170 \mathrm{~kg} / \mathrm{m}^{3}, c_{\mathrm{r}}=930 \mathrm{~m} / \mathrm{s}$. The tests were performed at room temperature. The results are summarised in table 1 . The fracture energy is around $3 \mathrm{~kJ} / \mathrm{m}^{2}$ which is three times lower than the quasi static fracture energy under dominating plane stress conditions. The crack velocity at branching is nearly $\dot{a} / c_{r} \approx 0.6$. The accuracy on the crack velocity measurement should be increased in the future.

Table 1: Result from RCP tests with the strip specimen.

\begin{tabular}{|c|c|c|c|}
\hline Temperature $\left({ }^{\circ} \mathrm{C}\right)$ & Crack velocity $(\mathrm{m} / \mathrm{s})$ & $\mathrm{G}_{\mathrm{D}}\left(\mathrm{kJ} / \mathrm{m}^{2}\right)$ & Branching \\
\hline 24 & 500 & 3.2 & at $\mathrm{a}_{0}+8 \mathrm{~mm}$ \\
\hline 25 & 580 & 2.0 & at $\mathrm{a}_{0}+63 \mathrm{~mm}$ \\
\hline 25 & 560 & 3.1 & no \\
\hline 27 & 600 & 3.9 & no \\
\hline 23 & $<1$ (static) & 10 & no \\
\hline
\end{tabular}




\subsection{Comparison with a quasi static test}

In the static case it is not possible to initiate a single propagating crack when the strip specimen has a sharp initial notch. Indeed, when the load increases, the crack tip blunts and whitens, indicating cavitation and damage $[14,15]$ in the process zone, and initiation is followed by an unstable propagation and multiple branching. Therefore the fracture energy was measured with a compact tension (CT) specimen and a J-type analysis, the loading being a displacement control of the pins. The dimension of the CT specimen was $100 * 100 \mathrm{~mm}^{2}(\mathrm{~W}=82 \mathrm{~mm})$ and the normalised initial crack length was $\mathrm{a}_{0} / \mathrm{W}=$ 0.4 . The thickness was $2.9 \mathrm{~mm}$ in order to have similar conditions of dominating plane stress condition. Of course the triaxiality is not well defined contrarily to thicker specimens where a plane strain conditions dominates in the near tip field. Moreover, the triaxility of the stress state is related to the second spatial derivative of the stress which globally increases with the crack velocity in the near tip field. Indeed, similar materials tested under dominating plane strain conditions [16] exhibit fracture energy in the same range that those measured during RCP. Although the present RCP results may have been compared to those obtained for dominating plane strain conditions, the main parameter to vary herein is the crack velocity, the dimension of CT and strip specimens being is the same range. Figures 8 and 9 indicate that the fracture energy increases with the whitened zone. It should be noticed on Fig. 9 , path 3, that the crack accelerated while the specimen released the strain energy and the whitened zone decreased during acceleration. As expected, the quasi static fracture energy under dominating plane stress condition is significantly greater than that measured during RCP.

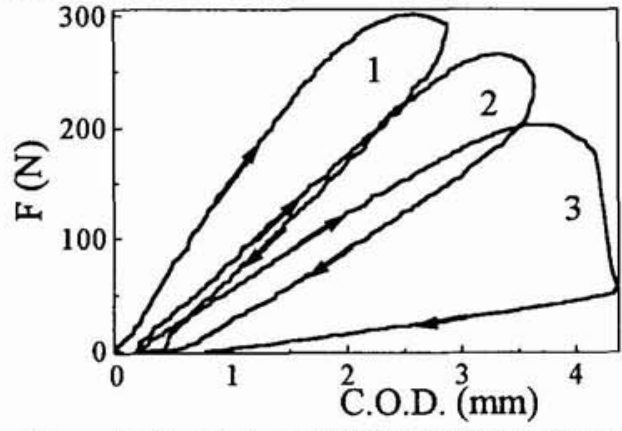

Figure 8: J-type test on a RT-PMMA CT specimen of size $100 * 100 * 2.9 \mathrm{~mm}^{3} . \mathrm{J}_{1}=11 \mathrm{~kJ} / \mathrm{m}^{2} ; \mathrm{J}_{2}=15 \mathrm{~kJ} / \mathrm{m}^{2}$; $\mathrm{J}_{3}=8 \mathrm{~kJ} / \mathrm{m}^{2}$.

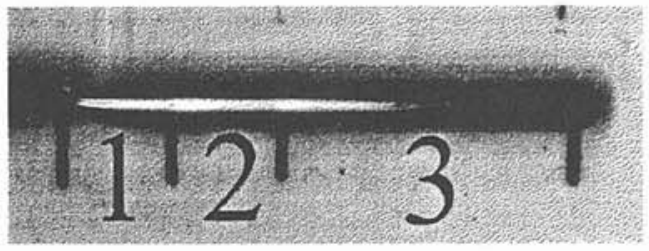

Figure 9: Process zone, whitened, after three quasi static propagation's and arrests (black lines) in a RT-PMMA. $\Delta \mathrm{a}_{1}$ $=6.5 \mathrm{~mm} ; \Delta \mathrm{a}_{2}=5.5 \mathrm{~mm} ; \Delta \mathrm{a}_{3}=17.5 \mathrm{~mm}$.

\section{CONCLUSION}

The strip specimen allows the measurement of the fracture energy during steady state propagation. It is a useful tool to analyse the minimum energy density leading to a RCP. However, several details need still some developments. The dynamic energy released rate for a finite strip should be numerically computed to have more accurate experimental results. The boundary and unloading conditions and the crack velocity during RCP must be precisely known. The effect of stress triaxiality at the crack tip related to the thickness of the specimen and to the crack velocity is still controversial.

\section{REFERENCES}

[1] Béguelin, P. and Kausch, H. H., J. Mat. Sci., 29, (1994), pp.91-98.

[2] Greig, J. M., Leevers, P. S. and Yayla, P., Eng. Fract. Mech., (1992).

[3] Yayla, P. and Leevers, P. S., Eng. Fract. Mech., (1992).

[4] Greenshields, C. J. and Leevers, P. S., Int. J. Fract., 79, (1996), pp. 85-95. 
[5] Takahashi, K. and Arakawa, K., Exp. Mech., 27, (1987), pp. 195-200.

[6] Freund, L. B. and Rosakis, A. J., J. Mech. Phys. Solids, 40, (1992), pp. 699-719.

[7] O'Donoghue, P. E., Green, S. T., Kanninen, M. F. and Bowles, P. K., Comp. Struct., 38, (1991), pp.501-513.

[8] Wheel, M. A. and Leevers, P. S., Int. J. Fract., 61, (1993), pp. 331-348.

[9] Wheel, M. A. and Leevers, P. S., Int. J. Fract., 61, (1993), pp. 349-359.

[10] Nilsson, F., Int. J. Fract. Mech., 8, (1972), pp.403-411.

[11] A. Ivankovic, I. Demirdzic, J. G. Williams and P. S. Leevers, Int. J. Fract., 66, (1994), pp. 357371.

[12] Zhou, F. and Shioya, F., Int. J. Fract., 80, (1996), pp. 33-44.

[13] Freund, L. B., J. Mech. Phys. Solids, 20, (1972), pp. 129-140.

[14] Schirrer, R., Fond, C. and Lobbrecht, $A$., J. Mat. Sc., 1996, 31(24), pp. 6409-6422.

[15] Fond, C., Schirrer, R., Lobbrecht, A., Int. J. Fract., 1996, 77, pp. 141-159.

[16] Béguelin, P., Approche Expérimentale du Comportement Mécanique des Polymères en Sollicitation Rapide, Ph. D. Thesis n 1572 , Ecole Polytechnique Fédérale de Lausanne (Switzerland), (1996). 